\title{
Eficiencia energética en el sector residencial de la Ciudad de Cuenca, Ecuador
}

\section{María T. Baquero L ${ }^{(D)}$, Felipe Quesada M.}

Proyecto Método de certificación de la construcción sustentable de viviendas ${ }^{1}$.

Maestría en Construcciones, Facultad de Arquitectura y Urbanismo, Universidad de Cuenca, Cuenca, Ecuador. Autor para correspondencia: maitebaquero7@gmail.com

Fecha de recepción: 6 de agosto 2016 - Fecha de aceptación: 18 de octubre 2016

\section{RESUMEN}

El objetivo de la presente investigación fue determinar en qué medida se puede reducir el consumo de energía en el sector residencial de la ciudad de Cuenca, manteniendo óptimas condiciones de confort. El estudio se centra en la definición de indicadores de eficiencia energética para la vivienda, mediante la determinación de la demanda de energía y la definición de los factores de mayor consumo, usando un enfoque cualitativo y cuantitativo. Se realizaron encuestas en 280 viviendas del sector residencial de la ciudad de Cuenca. Paralelamente se monitorizó el consumo de luz y la calidad del ambiente interior de 6 viviendas y se las analizó mediante simulaciones. Los resultados fueron analizados y comparados con los estándares nacionales e internacionales de eficiencia, y utilizados como base para la definición de las estrategias de reducción de consumo de energía y la definición de indicadores mínimos de consumo de energía eléctrica.

Palabras clave: Eficiencia energética, consumo eléctrico, indicadores de consumo de energía, área residencial, Cuenca.

\begin{abstract}
The objective of the research presented herein was to determine how far in the residential area of the City of Cuenca the consumption of energy can be reduced, maintaining optimal comfort conditions. In addition, the research focused on the definition of energy efficiency indicators for residential homes. The study involved determination of the energy demand and assessment of the major consumption factors using both qualitative and quantitative approaches. Surveys were conducted in 280 households of the residential area of Cuenca. Parallel, light consumption and indoor environmental quality was monitored in 6 houses and reconstructed using simulation models. The results were analysed and compared with national and international standards of efficiency, and used as a basis for defining strategies for reducing energy consumption and the definition of indicators of minimum power consumption.
\end{abstract}

Keywords: Energy efficiency, electrical consumption, energy consumption indicators, residential area, Cuenca.

\section{INTRODUCCIÓN}

La necesidad de recursos energéticos en el mundo ha aumentado debido al crecimiento poblacional, el desarrollo de la industria y el transporte. En los últimos 44 años el consumo de energía se duplicó a nivel mundial, mientras que la población creció de 3,700 millones en 1971 a 7,318 millones actualmente

1 Proyecto financiado por la Dirección de Investigación de la Universidad de Cuenca (DIUC). 
(United States Census Bureau, 2015) y se estima que se incrementará hasta 9,100 millones en el 2050 según la ONU (United Nations, 2015).

La Conferencia de las Naciones Unidas sobre el Medio Ambiente y el Desarrollo, realizada en 1992 en Río de Janeiro, estableció la importancia de un desarrollo de las naciones que sea sostenible y en armonía con la naturaleza. Con este propósito, se creó el Programa de acción Agenda 21 (ONU, 2016); del cual Ecuador participó conjuntamente con otros 177 países. Posteriormente en 1997 se firmó el Protocolo de Kioto, con el objetivo de que los países industrializados y de economías en transición reduzcan sus emisiones de gases efecto invernadero, por debajo del volumen de 1990 (MINETUR, 2015). Aunque las cantidades de emisiones en América Latina, están muy por debajo de las producidas en el resto del mundo, la región tiene un rol importante pues su nivel de aportación se está incrementando y a la vez es susceptible a los efectos que se derivan del cambio climático causado por las emisiones globales (Ministerio de Ambiente del Ecuador, 2013). Además, según la AIHE (2015), en América Latina el consumo de petróleo aumenta en un promedio del 2.3\% anualmente.

En el Ecuador la población ha pasado de 6,248,831 en 1971 a 16,560,348 en la actualidad (INEC, 2016). Dentro del marco de la sustentabilidad, su actual constitución declara que sobre las bases del "buen vivir" se encuentra el derecho a un "hábitat seguro y saludable, que es de interés público la preservación del ambiente y garantiza un modelo sustentable de desarrollo, ambientalmente equilibrado que asegure la satisfacción de las necesidades de las generaciones presentes y futuras" (Asamblea Nacional del Ecuador, 2008). Además, el país se encuentra en transición de un cambio en su matriz energética. Actualmente, el $49.5 \%$ de la generación de energía eléctrica proviene de hidroeléctricas, mientras el $46.5 \%$ aún proviene de fuentes fósiles como es la energía térmica (MCI, turbo gas y turbo vapor) (CONELEC, 2015a). En la Figura 1 se presenta el consumo de energía eléctrica por sector de los años 2012 al 2015.

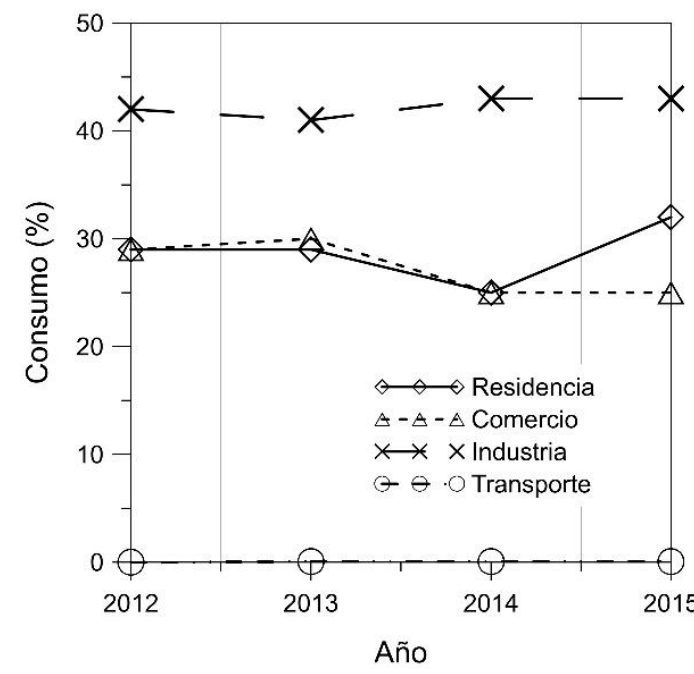

Figura 1. Consumo de energía eléctrica por sector (Ministerio Coordinador de Sectores Estratégicos, 2015).

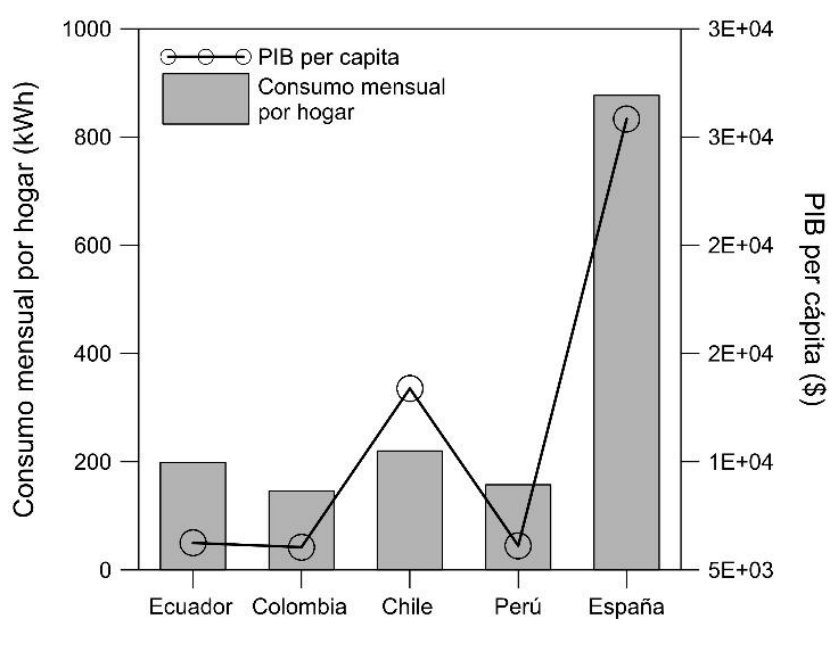

Figura 2. Consumo de energía eléctrica promedio por hogar en Ecuador, Colombia, Chile, Perú y España, comparado con el PIB (2015) per cápita.

El consumo de energía eléctrica en Ecuador en el año 2000 fue de 7,885 GWh subiendo a 12,196 GWh para el 2014, lo que indica un aumento del 154\%; mientras que el consumo promedio por hogar se encuentra en $198.7 \mathrm{kWh}$ (INEC, 2014). Si se compara con los datos de algunos países dentro de la región de América del Sur como son Colombia (SUI, 2015), Perú (Green Energy Consultants \& Services, 2010), Chile (Ministerio de Energía de Chile, 2015) y con otros a nivel mundial como España (IDAE, 2011), que representa a un país de una situación geográfica y de desarrollo diferente, el Ecuador se encuentra ligeramente sobre el promedio de la región, en la cual Chile resulta el de mayor consumo, lo que se puede apreciar en la Figura 2 junto con los datos del PIB per cápita del año 2015 (Banco Mundial, 2015). En este gráfico se puede observar que Chile es el país de mayor consumo de energía per cápita de la región, esto está relacionado directamente al PIB per cápita, es decir, al nivel de 
crecimiento económico (Barreto \& Campo, 2012; Robledo \& Olivares, 2013). Los subsidios al gas y electricidad en el Ecuador, han hecho posible el nivel de despilfarro de energía, por lo que, si algún día estos se eliminan y se continúa con los niveles de consumo de energía como hasta el día de hoy, habrá un gran impacto en la economía de las familias. Es meritorio entonces, la búsqueda de alternativas y soluciones al respecto.

Tanto, Chile y España han desarrollado sistemas de certificación energética en donde se han definido los mínimos valores de consumo de energía que se deberían alcanzar. Por otro lado, Colombia, Perú y Ecuador, aunque no tienen establecidos sistemas de certificación o indicadores de mínimo consumo energético, han determinado en su legislación el consumo mínimo que deberían tener las viviendas para acceder al sistema de subsidios o descuentos, como se puede ver en la Figura 3. En Ecuador el Decreto Ejecutivo No. 451-A SRO No. 125 (12 de julio 2007) dispone "la aplicación del Subsidio Tarifa Dignidad" (Agencia de Regulación y Control de Electricidad del Ecuador, 2016), en Colombia, la Resolución 355 determina el "Consumo de subsistencia” (Ministerio de Minas y Energía de Colombia, 2004), mientras que en Perú el Fondo de Compensación Social Eléctrica (FOSE), basado en la Ley N $\mathrm{N}^{\mathrm{0}} 275.010$, establece un esquema de subsidios (OSINERGMIN, 2013).

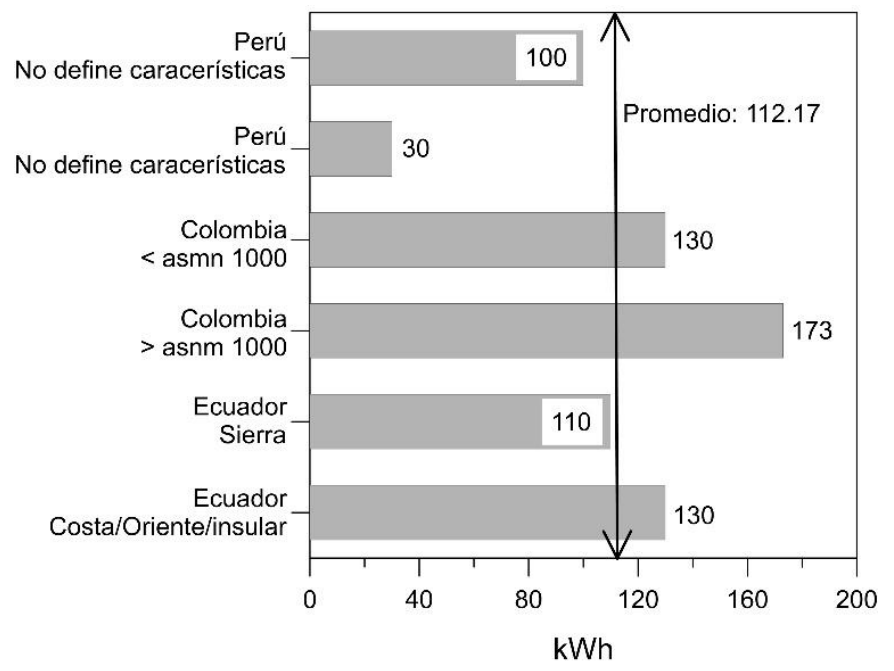

Figura 3. Consumos mínimos por hogar sujetos a subsidios y descuentos en Colombia, Perú y Ecuador.

Según los análisis de los estudios realizados por el BID (2014) la población urbana de Cuenca pasará de 459,057 habitantes en el 2010 a 901,499 habitantes en el 2050. Actualmente el $99.6 \%$ de la población urbana de Cuenca tiene acceso a fuentes de energía eléctrica en su vivienda, la misma que está conectada a la red Centrosur (BID, 2014). Cuenca es una ciudad muy favorecida por su clima templado, donde el promedio de temperatura es de $15^{\circ} \mathrm{C}$ sin presentar temperaturas extremas a lo largo del año, según la Estación Meteorológica del CEA de la Universidad de Cuenca (Baquero, 2013). Por esta razón, en las viviendas no se ve la necesidad de sistemas de climatización, factor que produce el mayor consumo de energía a nivel residencial en la mayoría de países del mundo que se han interesado en la eficiencia energética (Pérez-Lombard et al., 2008). En cuenca, las emisiones de gases de efecto invernadero (GEI) son 2.42 toneladas anuales de $\mathrm{CO}_{2}$ per cápita; esto ubica a la ciudad en un nivel verde, según la metodología del Índice de Ciudades Emergentes y Sostenibles (ICES) (BID, 2014). El consumo promedio de energía eléctrica por hogar en la zona urbana de Cuenca es de $243.7 \mathrm{kWh}$ por vivienda (INEC, 2014). Sin embargo, en Cuenca, el sector residencial es el que más consume energía eléctrica, con un porcentaje del $37.76 \%$, seguido del industrial con el $32.47 \%$, el comercial con el 15.68\%, público $8.58 \%$ y otros con el $5.51 \%$ (Centrosur, 2015).

Este estudio ha tomado como referencia algunas Normas Internacionales como la ISO 15392, ISO 21931-1 e ISO 21929-1 (2008, 2010 y 2011, expectativamente); por otro lado se analizó la normativa de España que mediante el Código Técnico de la Edificación (CTE) (Ministerio de Fomento de España, 
2013 \& 2015), han desarrollado el DBHE (Documento Básico HE, Ahorro de Energía) en el cual se establecen las reglas para cumplir con las exigencias básicas de habitabilidad; y de igual manera la normativa de Chile, en donde el Instituto Nacional de Normalización de Chile (INN) ha desarrollado en el 2007 las normas NCh3149 "Diseño ambiental de edificios" y NCh853 "Acondicionamiento térmico, envolvente térmica de edificios, cálculo de resistencias y transmitancias térmicas", y en el 2008 la norma NCh1079 "Zonificación climático habitacional para Chile y recomendaciones para el diseño arquitectónico". Posteriormente en el año 2013 el Ministerio de Vivienda y Urbanismo de Chile lanzó la Etiqueta Calificación Energética de Viviendas (CEV) (MINVU, 2013 \& 2014).

Se ha analizado también la normativa nacional, en la cual el Instituto Ecuatoriano de Normalización (INEN) formula documentos normativos asociados al etiquetado y certificación de la eficiencia energética de electrodomésticos, equipos y luminarias (INEN, 2015). Además emite la NTE INEN 2506, con enfoque a la regulación de la balanza energética de edificios (INEN, 2009), sobre cual se basa la NEC 11, Capítulo 13: Eficiencia Energética en la Construcción en Ecuador (Gobierno Nacional del Ecuador, 2011). Esta normativa aún no está en vigencia y se encuentra en proceso de actualización.

En cuanto a los métodos de evaluación de eficiencia energética, la Dirección de Desempeño Energético en Edificios (EPBD), que recopila los principios y objetivos generales para el desarrollo de investigaciones en eficiencia energética en los edificios dentro de la Unión Europea, ha solicitado a los países miembros que implementen certificados de desempeño energético para edificios (De Boeck et al., 2015; Thiers \& Peuportier, 2012), lo que ha incentivado a la generación de algunos métodos de evaluación de aplicación voluntaria a nivel internacional en países como Gran Bretaña, Estados Unidos, Francia, Japón, Alemania y España, como son BREEAM, LEED-H, QUALITEL, CASBEE, PASSIVHAUSS y VERDE respectivamente. En estos, la valoración y la definición de parámetros están ligadas a las características y necesidades ambientales, económicas y sociales de cada país. Dentro de este tema, Quesada (2014) realiza una comparación entre 5 métodos internacionales (BREEAM-MR, LEED-H, QH\&E, CASBEE, y VERDE), siendo LEED-H y BREEAM-MR los que mayor importancia dan a la eficiencia energética. Además, define que los métodos de evaluación sirven como instrumentos que proporcionan indicadores cuantitativos del desempeño y como herramientas de calificación para determinar el nivel de rendimiento de un edificio. Dentro de los principales indicadores que estos métodos asignan al tema de la eficiencia energética están: la iluminación artificial interna y externa, iluminación natural, electrodomésticos y uso de energías renovables.

Esta investigación se desarrolla teniendo en cuenta que el consumo de energía depende de varios factores, entre ellos el social, la eficiencia de los sistemas y tecnologías utilizadas, el tamaño familiar (Lutzenhiser, 1992), el comportamiento de los ocupantes y de las características propias de cada localidad (Forsberg \& von Malmborg, 2004). Este estudio tiene como objetivo establecer indicadores estándar para evaluar la eficiencia energética de las viviendas del sector residencial de Cuenca, basándose en el consumo actual y la reducción máxima de este, y que a la vez satisfaga el confort de la edificación. Con este objetivo en mento, se plantea la siguiente pregunta de investigación: ¿Cuál es el mínimo consumo de energía eléctrica en el sector residencial de Cuenca que garantice un óptimo confort interior? Para esto, se utilizará una metodología mixta que involucre datos cualitativos y cuantitativos, ya que según Brunsgaard et al. (2011), aportan dos tipos diferentes de conocimiento; generando una visión más completa y holística de la calidad interior de las viviendas y su consumo de energía eléctrica. El uso de este tipo de metodología se ha vuelto popular desde 1980 (Bryman, 2008). Es importante combinar los dos recursos ya que las mediciones pueden indicar cómo es el consumo energético de una vivienda pero no pueden decir el por qué, sin embargo los usuarios podrían dar una explicación mediante sus respuestas a las encuestas (Brunsgaard et al., 2011). 


\section{MÉTODOS}

\subsection{Primera etapa: Encuesta general al sector residencial de Cuenca}

El estudio se realizó en el sector urbano residencial de la ciudad de Cuenca, Ecuador, capital de la Provincia del Azuay, en la región Sierra, ubicada a una altitud de $2530 \mathrm{msnm}$. Las coordenadas geográficas de la ciudad son $2^{\circ} 52^{\prime}-2^{\circ} 54^{\prime}$ latitud Sur y $78^{\circ} 59^{\prime}-79^{\circ} 01^{\prime}$ longitud Oeste Greenwich. La temperatura varía entre 10.1 y $21.6^{\circ} \mathrm{C}$. El valor promedio de la humedad relativa varía entre 40 y $85 \%$, las horas del brillo del sol (heliofanía) tienen porcentaje que van del 33 al 45\%, con una nubosidad promedio mensual que varía entre 6 y 7 octavas (gran cantidad de nubes). La radiación solar es de alrededor de $4.35 \mathrm{kWh} \mathrm{m}^{-2}$ día $^{-1}$. El promedio anual de precipitaciones es de $69.98 \mathrm{~mm} \mathrm{~m}^{-2}$. La dirección predominante de los vientos es Noreste y la velocidad promedio del viento es de $9.29 \mathrm{~km} \mathrm{~h}^{-1}$, según datos de la Estación Meteorológica del CEA de la Universidad de Cuenca (Baquero, 2013).

Con el fin de analizar la demanda de energía eléctrica de la ciudad de Cuenca, en una primera etapa se realizaron encuestas a nivel general del sector residencial. El diseño específico de muestreo estadístico que se ha establecido es del tipo probabilístico, polimetálico y aleatorio de viviendas particulares dentro del universo conformado por el sector urbano de la ciudad de Cuenca, considerando sus 15 parroquias. La muestra poblacional es de 280 viviendas distribuidas en toda la zona urbana de Cuenca, a las cuales se les aplicó la encuesta general, basándose en una ficha con preguntas cerradas. Se obtuvieron datos cuantitativos sobre variables cualitativas como son los hábitos de uso, satisfacción o expectativas de calidad de los servicios a los usuarios, en especial sobre iluminación. Además, se realizaron preguntas sobre las características de los electrodomésticos y luminarias, tomando como referencia, para la estructuración de la ficha, varias fuentes como SENER (2011), Cuchí (2003), INEC (2014), Martínez (2010), Aldossary et al. (2015) y Barr et al. (2005).

\subsection{Segunda etapa: casas de estudio}

En una segunda etapa se realizó el análisis de casos específicos, tomando como muestra a 6 viviendas. De acuerdo a la revisión del estado del arte se determinó este número de viviendas como óptimo para establecer una idea de lo que ocurre en el sector residencial de la ciudad de Cuenca, ya que existen pocos estudios sobre las edificaciones residenciales, los cuales generalmente se han centrado en el análisis de una sola vivienda (Dili et al., 2010; Laverge et al., 2011; Taleb \& Sharples, 2011). Sin embargo, estudios similares (Brunsgaard et al., 2011) han demostrado que la selección adecuada de 3 viviendas puede conducir a resultados importantes, por lo tanto en esta ocasión se optó por un número de 6, las cuales fueron seleccionadas de un grupo de 11 viviendas que forman parte del estudio que realiza el proyecto de investigación: "Método de Certificación de la Construcción Sustentable de Viviendas" ganador del XIII Concurso Universitario de Proyectos de Investigación convocado por la Universidad de Cuenca, en el cual el presente estudio colaboró con los resultados. Las 6 viviendas se seleccionaron en base a su orientación, estado de conservación y su ocupación. Con la finalidad de identificar las principales fuentes de consumo de energía eléctrica, se realizaron mediciones, simulaciones y encuestas basadas en fichas de preguntas cerradas, a cada vivienda de estudio. Además, se compararon los resultados con las planillas de consumo eléctrico de cada vivienda.

\subsection{Etapa tres: Resultados y propuesta}

Finalmente, mediante la obtención de información y datos reales del consumo eléctrico, así como la identificación de los principales factores que lo determinan, se realizó la evaluación y planteamiento de estrategias para conseguir una demanda eficiente, a la vez que se cumplan los requisitos de confort de las viviendas, dentro de los objetivos de sustentabilidad y eficiencia energética local, regional y nacional. 


\section{MATERIALES}

\subsection{Herramientas utilizadas para las mediciones}

Para la medición y monitorización del consumo energético de las 6 viviendas de estudio $(\mathrm{kWh})$ se utilizaron equipos contadores instantáneos de electricidad con las siguientes características:

- Constan de un transmisor, un monitor inalámbrico y sensores (máximo 3 sensores por equipo).

- El sensor se lo acopla al cable fase de la caja de distribución (en este caso se instaló solo al correspondiente a tomacorrientes pues el equipo no diferencia entre consumo por iluminación o por electrodomésticos). La electricidad que se utiliza en la vivienda pasa a través del sensor que debe conectarse al transmisor, este envía la información de forma inalámbrica al monitor para su visualización instantánea o almacenamiento.

- La frecuencia de transmisión de datos es de 433.5 Mhz, en intervalos de tiempo de 6, 12 o 18 s. El alcance de transmisión entre el transmisor y el monitor es de 40-70m.

- Según las especificaciones técnicas tienen una precisión mayor al $90 \%$.

\subsection{Herramientas utilizadas para las simulaciones}

Para medir la calidad de iluminación interior y la demanda de energía que necesitaría cada vivienda, se ha utilizado el software de Diseño de Construcción Sustentable Ecotect Analisis de Autodesk, versión 2011, que se basa en el Método de las Admitancias, desarrollado por el Chatered Institute of Building Service Engineers (CIBSE). Este método aplica un algoritmo térmico flexible, sin restricciones en cuanto a la geometría de los edificios o el número de zonas térmicas. Se aplican las características a los elementos constructivos del modelo y se divide cada vivienda en zonas térmicas, para definir una respuesta dinámica en régimen transitorio. Además, se incorporó un archivo climático de la ciudad con los datos de la Estación Meteorológica del CEA de la Universidad de Cuenca y del Aeropuerto Mariscal Lamar de Cuenca.

\section{RESULTADOS}

\subsection{Encuesta general al sector residencial de Cuenca}

De la aplicación de la encuesta general a las 280 viviendas se obtuvieron los siguientes resultados:

Características generales:

- El 80\% de las viviendas encuestadas son adosadas, y el $46 \%$ de las viviendas encuestadas tienen una antigüedad mayor a 10 años.

- El promedio de personas que habitan por vivienda es de 4.08.

Electrodomésticos y hábitos de consumo:

- El 68\% de los encuestados desconectan los electrodomésticos cuando no están en uso.

- En cuanto a la antigüedad 36\% de las refrigeradoras tienen una edad de más de 10 años.

- Sobre el etiquetado de eficiencia energética, el $87 \%$ de los encuestados consideran que es importante que los electrodomésticos tengan características de ahorro energético al momento de adquirirlos; sin embargo, solamente el $41 \%$ de los encuestados poseen refrigerador con etiqueta de eficiencia energética.

- Para el calentamiento de ACS el 59\% de los encuestados utiliza calefón a gas.

Percepción de confort:

- Sobre la percepción térmica el 65\% de los encuestados consideran que su vivienda es confortable (ni calurosa ni fría). Sin embargo, en cuanto a sistemas de climatización, se pudo obtener que tan solo el $2 \%$ utiliza algún sistema de calefacción. De estos, el $80 \%$ utiliza calefactor eléctrico portátil y el $20 \%$ calefactor a gas, sobre todo en los meses de julio, agosto 
y diciembre. Aun así, el 13\% de los encuestados creen que necesitan calefacción en su vivienda.

- En cuanto a iluminación, el 93\% de los encuestados utiliza focos ahorradores. El 98\% asegura que apaga las luces al salir de una habitación, el 92.5\% abre las cortinas de las habitaciones durante el día para aprovechar la luz natural. El $41 \%$ de los encuestados considera que todos los ambientes de su casa se iluminan adecuadamente por la luz del día; sin embargo, el 33.3\% necesita encender la iluminación artificial en la mañana. En la Figura 4 se puede ver cuantas horas se enciende la iluminación artificial en el día y la tarde.

Aspectos económicos y sostenibilidad:

- El 32\% considera muy importante que una vivienda ahorre energía, agua y que en su proceso de construcción cause mínimo impacto al ambiente, sobre todo el nivel socio económico alto; sin embargo, el $66 \%$ no estarían dispuestos a invertir en viviendas con estas características.

- Sobre el uso de energías alternativas, si bien el 32\% considera importante el uso de estos sistemas en la vivienda, el $100 \%$ de los encuestados no utiliza ninguno.

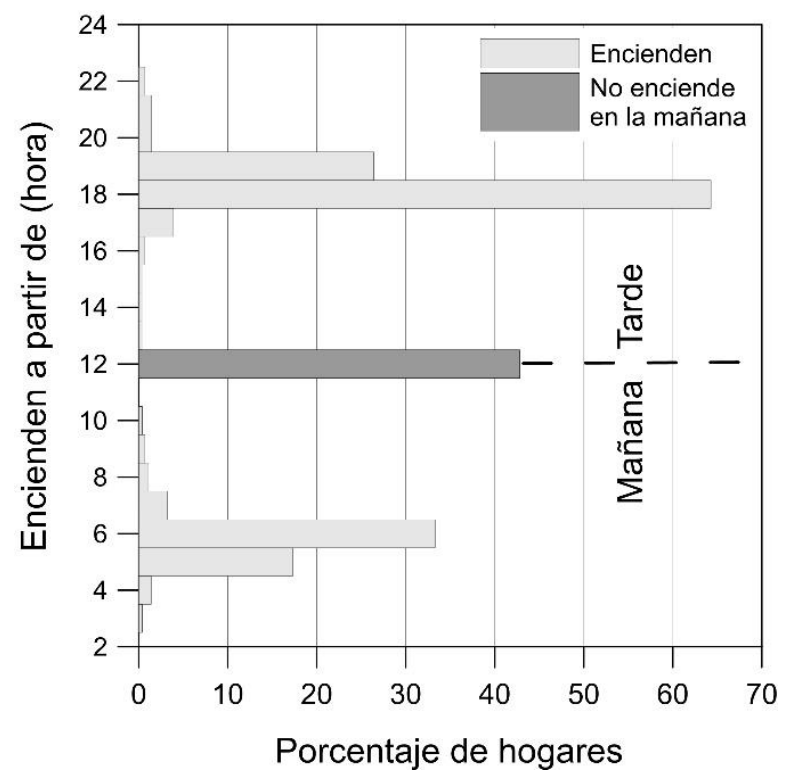

Figura 4. Distribución porcentual promedio de encendido de la iluminación eléctrica por día.

\subsection{Resultados de los casos de estudio}

Descripción de casos de estudio

En la Figura 5 se pueden ver las fotografías de las viviendas de estudio y sus características se resumen en la Tabla 1.

Tabla 1. Características de las viviendas de estudio. Levantamiento y entrevistas.

\begin{tabular}{llllll}
\hline Vivienda & $\begin{array}{l}\text { Orientación con } \\
\text { respecto al norte }\end{array}$ & $\begin{array}{l}\text { Forma de la } \\
\text { vivienda }\end{array}$ & Tipo de edificación & $\begin{array}{l}\mathrm{N}^{\circ} \text { de piso de } \\
\text { departamento }\end{array}$ & $\mathrm{N}^{\circ}$ de pisos \\
\hline 1 & Noroeste & $\mathrm{L}$ & $\begin{array}{l}\text { Departamento } \\
\text { adosado }\end{array}$ & 2 & 1 \\
\hline 2 & Oeste & Rectangular & Adosada 1 lado & - & 2 \\
\hline 3 & Norte & Cuadrada & Adosada 1 lado & - & 2 \\
\hline 4 & Suroeste & Cuadrada & $\begin{array}{l}\text { Departamento } \\
\text { adosado }\end{array}$ & 2 & 1 \\
\hline 5 & Oeste & Rectangular & Departamento & 2 & 1 \\
\hline 6 & Noreste & Cuadrada & Adosada 2 lados & - & 2 \\
\hline
\end{tabular}




\begin{tabular}{|c|c|c|c|c|c|c|c|}
\hline Vivienda & $\begin{array}{l}\text { Área de construc- } \\
\text { ción }\left(\mathrm{m}^{2}\right)\end{array}$ & $\begin{array}{l}\text { Planta } \\
\text { baja }\left(\mathrm{m}^{2}\right)\end{array}$ & $\begin{array}{l}\text { Planta } \\
\text { alta }\left(\mathrm{m}^{2}\right)\end{array}$ & Habitantes & $\begin{array}{l}\text { Edad } \\
\text { (años) }\end{array}$ & $\begin{array}{l}\text { Dormitor- } \\
\text { ios }\end{array}$ & Baños \\
\hline 1 & 169.16 & 169.16 & - & 4 & 2 a 10 & 2 & 2 \\
\hline 2 & 438.19 & 339.36 & 98.83 & 4 & $>10$ & 4 & 4 \\
\hline 3 & 298.29 & 145.23 & 153.06 & 3 & $>10$ & 4 & 4 \\
\hline 4 & 74 & 74 & - & 2 & 2 a 10 & 2 & 2 \\
\hline 5 & 107.28 & 107.28 & - & 2 & $>10$ & 2 & 2 \\
\hline 6 & 171.21 & 87.23 & 83.98 & 5 & $>10$ & 3 & 3 \\
\hline
\end{tabular}

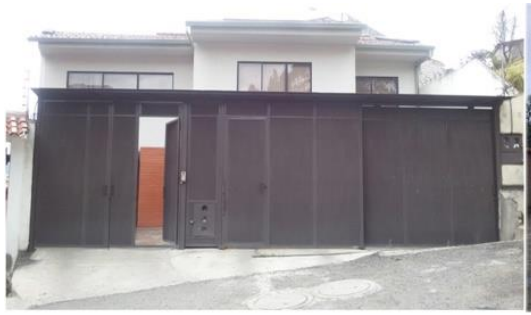

VIVIENDA 1

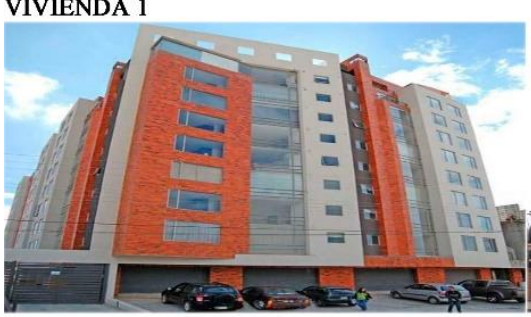

VIVIENDA 4

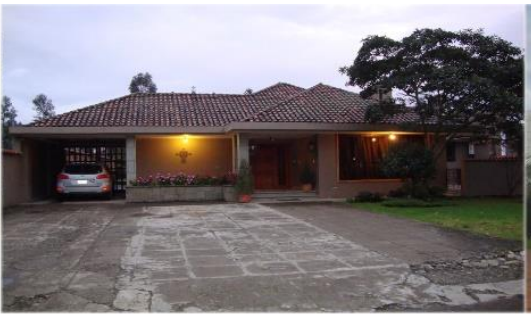

VIVIENDA 2

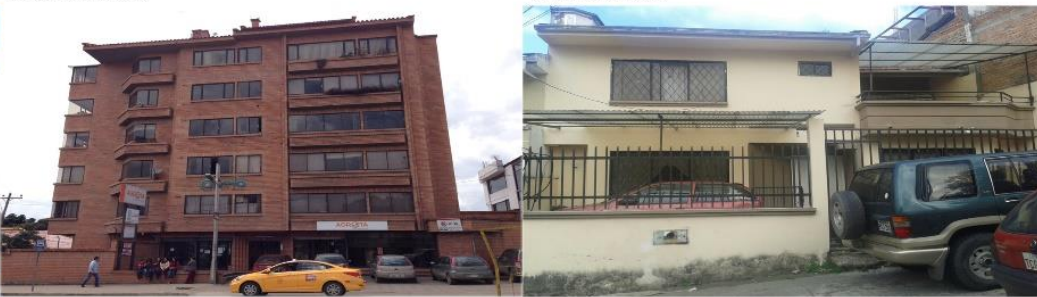

VIVIENDA 5

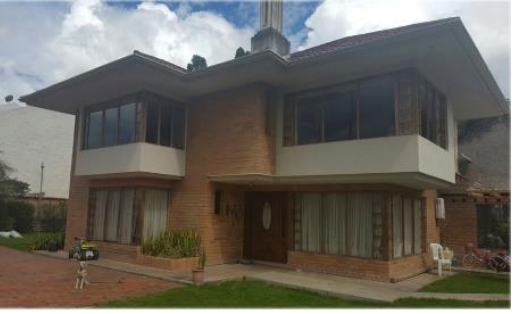

VIVIENDA 3

VIVIENDA 6

Figura 5. Fotografías de las viviendas de estudio.

Resultados de medición de consumo eléctrico en las viviendas de estudio

En la Tabla 2 y en la Figura 6 se presentan el consumo total de cada vivienda, así como el de tomacorrientes e iluminación.

\begin{tabular}{cccc}
\hline Vivienda & $\begin{array}{c}\text { Promedio } \\
\text { mensual } \\
\left(\mathrm{kWh} \mathrm{mes}^{-1}\right)\end{array}$ & $\begin{array}{c}\mathrm{kWh} \\
\mathrm{año}^{-1}\end{array}$ & $\begin{array}{c}\mathrm{kWh} \\
\mathrm{m}^{-2} \text { año }^{-1}\end{array}$ \\
\hline 1 & 242.00 & $2,904.00$ & 19.40 \\
2 & 304.50 & $3,654.00$ & 9.61 \\
3 & 269.12 & $3,229.44$ & 27.72 \\
4 & 36.39 & 436.70 & 5.95 \\
5 & 164.00 & $1,968.00$ & 19.67 \\
6 & 192.40 & $2,308.80$ & 28.41 \\
\hline $\begin{array}{c}\text { Prome- } \\
\text { dio }\end{array}$ & 201.40 & $2,416.82$ & 18.46 \\
\hline
\end{tabular}

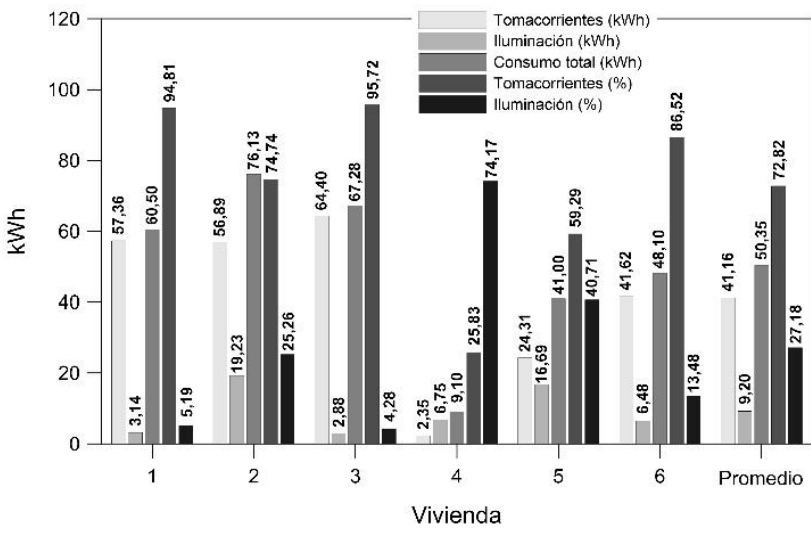

Tabla 2. Resultados de equipos de medición consumo de energía total de cada vivienda de estudio.

Figura 6. Consumo total de energía eléctrica en las viviendas de estudio por semana.

Entrevistas y levantamiento de cada vivienda de estudio

Sobre el confort lumínico y térmico de la vivienda se pidió a sus habitantes que establezcan su grado de satisfacción en los diferentes espacios en una escala del 1 al 7, siendo 1 muy satisfecho y 7 muy insatisfecho. La Figura 7 resume los resultados a esta pregunta. Además, sobre la iluminación artificial, 
ninguna de las viviendas de estudio utiliza sensores de luz, temporizadores o algún tipo de control de luminarias.

En cuanto a la iluminación natural, todas las viviendas tienen control sobre las cortinas y persianas de sus habitaciones y aseguran que las mantienen abiertas durante el día. Además, todos los usuarios de las viviendas, a excepción de los de la vivienda 6 , piensan que no falta iluminación natural en sus viviendas. Sin embargo, solo en las viviendas 2 y 4 no necesitan encender la luz en las mañanas, mientras que en las demás se encienden entre una y dos horas, mientras en la tarde y en la noche en todas las viviendas la encienden entre tres y cinco horas, la mayoría desde las $18 \mathrm{~h} 00$, como se puede apreciar en la Figura 8.

En cuanto al consumo de electrodomésticos de cada vivienda, basándose en la encuesta realizada, se ha realizado un análisis teniendo en cuenta la cantidad y frecuencia de uso de cada uno de ellos y sus hábitos de permanecer conectados. Este consumo depende de la potencia del electrodoméstico y del tiempo de uso. En la Figura 9 se observa su representación en el consumo total.
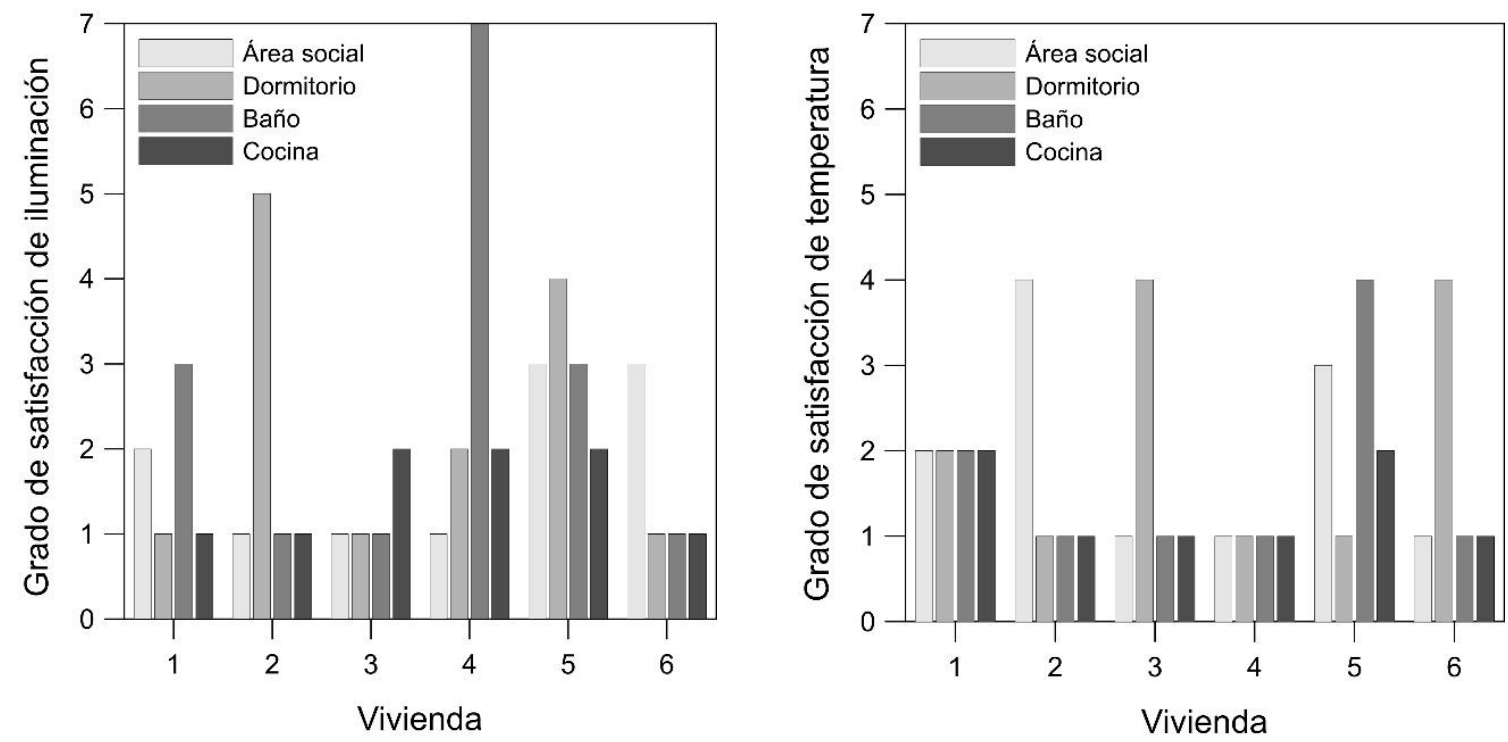

Figura 7: Grado de satisfacción de iluminación y temperatura (muy satisfecho 1 a muy insatisfecho 7).

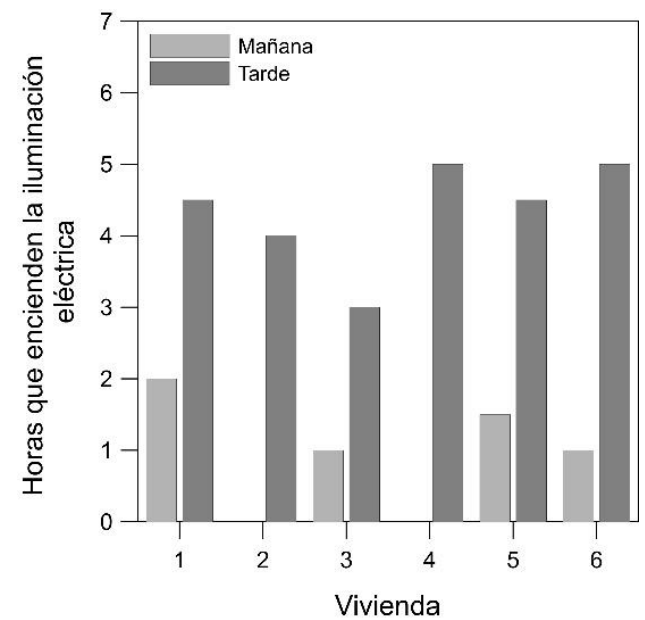

Figura 8. Horas que encienden la iluminación eléctrica por la mañana y por la tarde.

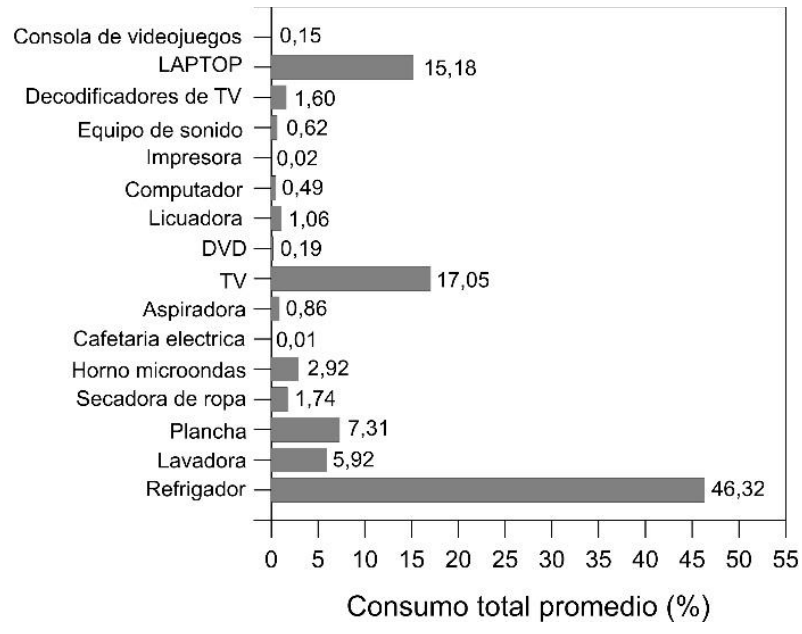

Figura 9. Porcentaje que representa cada electrodoméstico en el consumo total promedio. 


\section{Software para simulación}

Se han realizado simulaciones en el programa Ecotect Analysis (Autodesk, 2011) sobre la demanda energética que necesitaría cada vivienda para su climatización en caso de utilizar algún sistema (ninguna lo hace) y los niveles de iluminación natural. Estos resultados se presentan en la Figura 10.
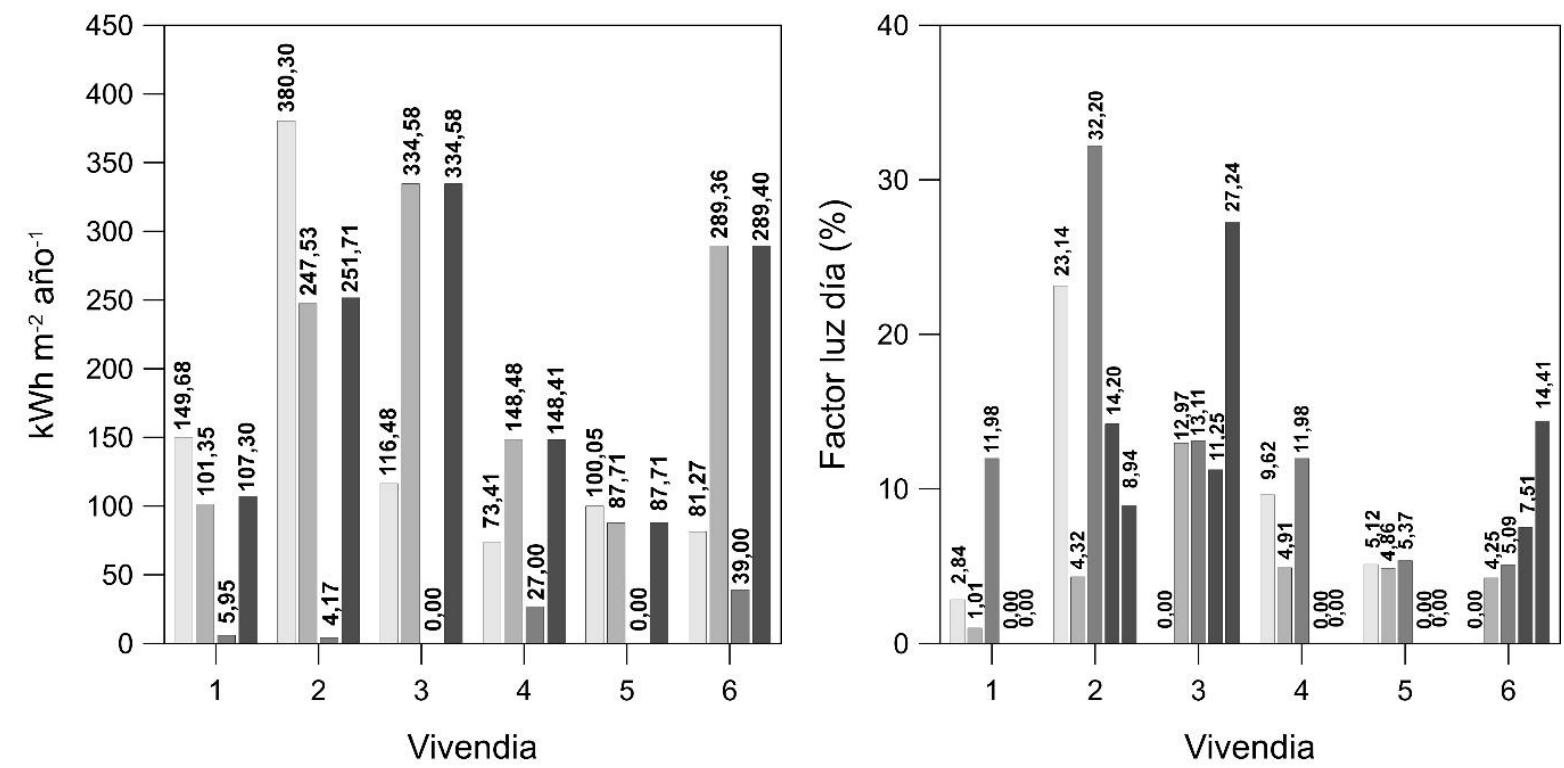

Figura 10. Resultados de simulaciones sobre demanda energética (izquierda) y factor luz día (derecho).

\section{DISCUSIÓN}

El consumo mensual promedio resultante del análisis de las 6 viviendas es de $201.4 \mathrm{kWh}$, y se puede establecer un indicador de $18.46 \mathrm{kWh} \mathrm{m}^{-2}$ año $0^{-1}$ como se presenta en la Tabla 2, con el cual es posible comparar las viviendas entre sí, a pesar de sus características diferentes en cuanto a tamaño, número de habitantes, nivel socioeconómico, entre otros factores que influyen en el consumo y hábitos energéticos de cada una de ellas. Si se lo compara con el promedio de consumo por hogar en los países de Latinoamérica (Fig. 2) esté se encuentra relativamente alto. Por otro lado, desglosando el consumo por hogar, se ha podido definir que alrededor del $72 \%$ del consumo viene dado por los tomacorrientes; es decir por los equipos y electrodomésticos, mientras que la iluminación representa tan solo un $28 \%$ en promedio del consumo total (ver Fig. 6). Esto depende principalmente de la eficiencia de los electrodomésticos, así como de las luminarias de cada vivienda y los hábitos de uso de sus habitantes.

En cuanto al levantamiento y características de cada vivienda, se ha analizado el tipo de luminarias y su relación con el consumo, siendo las viviendas 2 y 3 las que mayor potencia presentan ya que más del $50 \%$ de sus luminarias son de alto consumo en este caso dicroicos. También, se ha tenido en cuenta la superficie de ventanas. Según, el Gobierno Nacional del Ecuador (2011) en la zona climática ZT3, que es a la cual pertenece la ciudad de Cuenca, se recomienda que las fachadas principales tengan orientaciones Este y Oeste ya que maximizan la ganancia solar directa en la mañana o en la tarde. No todas las edificaciones estudiadas cumplen con este requisito pues si se analizan las horas que encienden la iluminación en la mañana, solamente en las viviendas 2 y 4 no necesitan encenderla ya que reciben luz natural pues sus ventanas se orientan hacia el este-oeste. Las otras viviendas necesitan encender la luz eléctrica en la mañana, lo que indica la importancia de una correcta orientación de las ventanas de la vivienda para aprovechar correctamente la luz natural.

En las entrevistas realizadas a los habitantes de las 6 viviendas se pudo obtener información sobre su percepción de confort y hábitos de consumo. La mayoría de los habitantes de las seis viviendas se encuentran satisfechos con la temperatura de sus hogares (Fig. 7). Ciertas inconformidades de 
temperatura se pueden deber a factores de diseño, orientación y materiales constructivos de la vivienda, que pueden constituir puntos de pérdidas de temperatura. Por ejemplo, los moradores de la vivienda 2 han indicado que su área social no es confortable en cuanto a la temperatura. Si analizamos este espacio se podría decir que se debe a que esta zona está cubierta por vidrio simple lo que posiblemente provoca grandes ganancias solares, pero a la vez grandes pérdidas de temperatura en horas de la noche. Además, las viviendas 2 y 3 son las que mayor área de ventanas tienen, lo que significa mayor área de pérdida de calor, ya que son ventanas de vidrio simple sin ningún tipo de aislamiento térmico. Los habitantes de la vivienda 6 manifestaron no estar muy satisfechos con la temperatura de sus dormitorios, esto puede deberse a que solamente el dormitorio principal tiene ventanas y recibe luz del día mientras que los otros dos no, lo cual no permite que ingrese calor natural a estos. En lo referente a ACS todas las viviendas utilizan calefón a gas para las duchas y ninguna utiliza algun tipo de energía alternativa; esto se debe a que existe un subsidio al GLP en el país, continúa siendo más económico esta manera de calentar el agua en las viviendas.

La Figura 9 presenta un desglose en cuanto al porcentaje de consumo que representa cada electrodoméstico siendo el refrigerador el de mayor consumo, seguido por la televisión, laptop, lavadora y plancha. Este consumo es determinado por la potencia y por el tiempo de uso. Aparte del refrigerador, que solamente las viviendas 2 y la 6 no poseen etiqueta energética, si se analiza el resto de electrodomésticos de alto consumo, p.e., el televisor, las seis viviendas presentan entre 1 y 8 horas de uso al día y cada vivienda tiene entre 1 y 3 televisores. La tendencia actual muestra el aumento de la demanda de equipos con pantalla cada vez más grande y de mayor potencia, siendo las pantallas LED las que menos consumen; además, se debe tener presente el consumo en reposo del aparato (Unidad de Planeación Minero Energética, 2014). El tercer equipo de mayor consumo es el computador portátil, al dejarlo conectado a la corriente durante sus horas de uso. Con respecto a este artículo electrónico, en la actualidad existen equipos de menor consumo como por ejemplo los que tienen la etiqueta "Energy Star" pueden ahorrar hasta el $60 \%$ de energía. La lavadora y secadora de ropa (eléctrica) también son electrodomésticos que consumen mucha electricidad y que se los puede sustituir con equipos con etiqueta energética.

En las simulaciones se obtuvieron resultados sobre el factor de luz natural o de luz día ${ }^{1}$. Según el Gobierno Nacional del Ecuador (2011) "el factor de luz natural no debe caer por debajo del 1\%, en el plano de trabajo a 3 m desde la pared de la ventana y a $1 \mathrm{~m}$ desde las paredes laterales". En la Figura 10 se puede ver que todas las viviendas cumplen está regla. También se analizó la demanda energética que requeriría para mantener el ambiente interior dentro de la zona de confort, que según el Gobierno Nacional del Ecuador (2011) debería estar entre 18 y $26^{\circ} \mathrm{C}$. La Figura 10 muestra que las viviendas 3, 6 y 2 son las que más $\mathrm{kWh} \mathrm{m}^{-2}$ año ${ }^{-1}$ necesitarían, sobre todo para calefacción.

\subsection{Definición de estrategias}

Para lograr reducir el consumo de energía eléctrica de las viviendas del sector residencial de Cuenca, de manera que no afecte el confort interior de la misma, se deben considerar varios elementos como es el consumo por electrodomésticos, luminarias, el diseño y orientación de la vivienda, así como los hábitos de consumo y la tecnología existente.

\section{Electrodomésticos}

Una de las estrategias básicas es la sustitución de electrodomésticos convencionales por aquellos de menor consumo, o que posean etiqueta de eficiencia energética (adhesivo que incluye información sobre el consumo energético del electrodoméstico mostrando una escala, las clases van de la $A$ a la $G$, siendo $A$ la más eficiente y $G$ la menos eficiente). Es muy importante saber que el consumo de energía de un aparato determinado, para prestaciones similares, puede llegar a ser casi tres veces mayor en los electrodomésticos de la clase G que en los de clase A, y más en clases superiores." (IDAE, 2011).

1 Relación entre la iluminancia, en un punto de un plano dado, debida a la luz recibida directa o indirectamente desde un cielo cuya distribución de luminancia se supone o se conoce, y la iluminancia sobre un plano horizontal procedente de un hemisferio de este cielo sin obstáculos. 
Además, se deben difundir y generar conciencia sobre buenos hábitos de uso y consumo como son:

- Apagar los electrodomésticos y desconectarlos cuando no se los esté usando.

- Mantener limpios los electrodomésticos, libres de polvo.

- No introducir alimentos calientes en el congelador.

- Los modelos de refrigerador que tienen el compartimiento del congelador en la parte superior consumen entre 7 y $13 \%$ menos energía que los modelos que lo tienen en un lado.

- Aprovechar al máximo la capacidad de la lavadora y secadora de ropa.

- Procurar secar la ropa al aire libre.

- Mantener bajos los niveles de iluminación en el lugar donde está instalado el televisor.

- Planchar la mayor cantidad de ropa en cada sesión.

- Permitir la circulación de aire por la parte trasera del frigorífico y que esté alejado de focos de calor o de la radiación solar directa.

- Descongelar el refrigerador antes de que la capa de hielo alcance $3 \mathrm{~mm}$ de espesor: podrá conseguir ahorros de hasta el 30\% (IDAE, 2011).

- La mayor parte de la energía que consume la lavadora (entre el 80 y el $85 \%$ ) se utiliza para calentar el agua, por lo que es muy importante recurrir a los programas de baja temperatura (IDAE, 2011).

- Centrifugar la ropa en la lavadora, antes de usar la secadora.

\section{Iluminación}

En las mediciones realizadas a las seis viviendas de estudio, se ha establecido que el $28 \%$ del consumo se debe a la iluminación, por lo tanto, es necesario una mejora en la eficiencia de las luminarias a través de la incorporación de sistemas de control y sobre todo el aprovechamiento de iluminación natural. Cuidando de dotar a cada espacio del nivel de iluminación (lux) adecuado, según las actividades que se realizan en él. La NEC 11 (Gobierno Nacional del Ecuador, 2011), así como QUALITEL (2012), determinan una eficiencia luminosa mayor o igual a $60 \mathrm{~lm} \mathrm{~W}^{-1}$ como mínima, mientras que BREEAM (Pinilla \& Orosa, 2011) exige un mínimo de $85 \mathrm{~lm} \mathrm{~W}^{-1}$. Esto depende del tipo de lámpara que se utiliza, ya sea incandescentes, halógenas, fluorescentes, led, etc. La eficacia luminosa de las bombillas incandescentes se sitúa entre los 12 y los $20 \mathrm{~lm} \mathrm{~W}^{-1}$, mientras que para las lámparas fluorescentes va desde los 40 a los $100 \mathrm{~lm} \mathrm{~W}^{-1}$ (IDAE, 2011).

Los focos fluorescentes reducen el consumo eléctrico entre 70 y $80 \%$ de energía en comparación con los focos tradicionales; además, duran entre 8 y 10 veces más que los convencionales proporcionando la misma luz (INEC, 2014). Por lo tanto, como otra de las estrategias básicas de ahorro de energía eléctrica, se recomienda la sustitución de luminarias convencionales como son los focos incandescentes y dicroicos por focos ahorradores fluorescentes o led.

En cuanto a la iluminación natural esta se aprovecha en mayor medida mediante consideraciones de diseño y una correcta orientación de la vivienda, pues lo ideal sería que la iluminación artificial se utilice solamente en la noche.

Se ha realizado un análisis en cada vivienda aplicando estrategias básicas como es la sustitución de electrodomésticos y luminarias por aparatos de menor consumo que se encuentran disponibles en el mercado local. Los resultados de no encender la iluminación artificial durante el día se presentan en la Figura 11. Este ahorro va del 31.1 al $70.94 \%$, estableciéndose un promedio de $46.25 \%$ de ahorro total con estas simples medidas, llegando a un indicador de $9.92 \mathrm{kWh} \mathrm{m}^{-2}$ año ${ }^{-1}$ como el mínimo al que se puede reducir el consumo eléctrico en la ciudad de Cuenca, equivalente a un consumo mensual promedio de $104.99 \mathrm{kWh}$. 


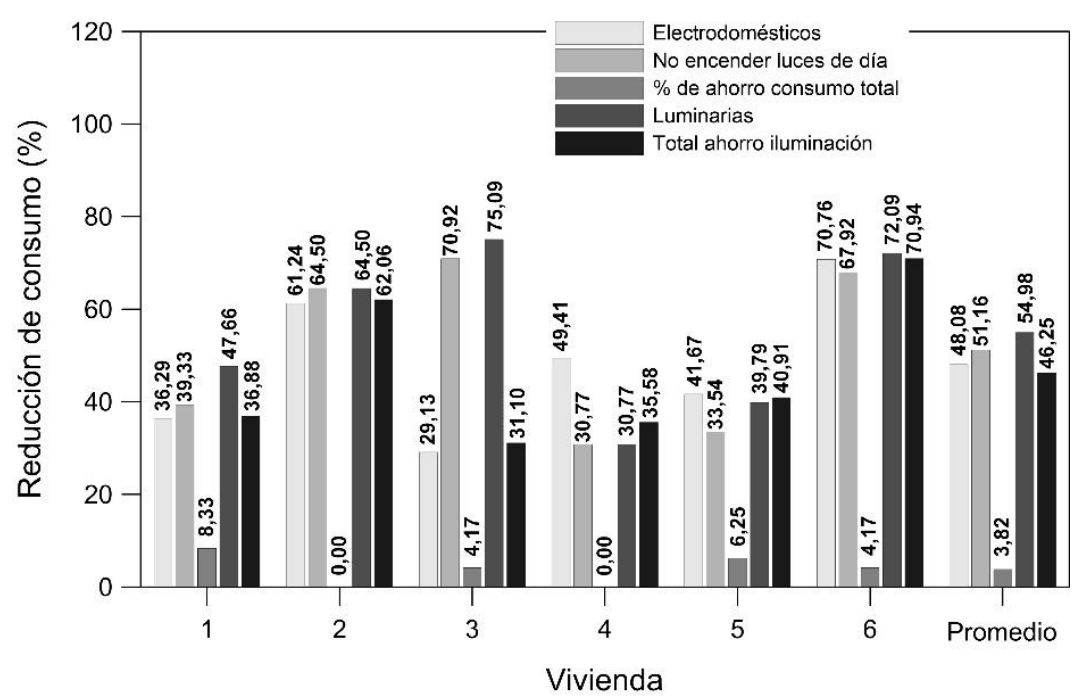

Figura 11. Porcentaje de ahorro que se logra con aplicación de estrategias básicas.

Para lograr un ahorro mayor se recomienda la aplicación de la tecnología existente como es la domótica, la utilización de energía renovable y además para proyectos de vivienda nueva o rehabilitación, debe exigirse la aplicación de los conceptos de diseño bioclimático.

\subsection{Definición de otras estrategias}

\section{Domótica}

Mediante este tipo de tecnología se puede gestionar inteligentemente la iluminación, climatización, agua caliente sanitaria y electrodomésticos, aprovechando mejor los recursos naturales, y de esta manera reducir el consumo eléctrico hasta un 80\% (CEDOM, 2008; Hernandez \& Meza, 2011). Dentro de las prestaciones de este tipo de servicios están:

- Sistemas de iluminación eficientes qué adaptan el nivel de iluminación en función de la variación de la luz solar, la zona de la casa o la presencia de personas, ajustándola a las necesidades de cada momento.

- Control automático inteligente de persianas y cortinas de la vivienda.

- Control automático del encendido y apagado de todas las luces de la vivienda.

- Sistemas de regulación de la calefacción: adaptan la temperatura de la vivienda en función de la variación de la temperatura exterior, la hora del día, la zona de la casa o la presencia de personas.

- Detección de la apertura y cierre de ventanas, qué avisan al usuario de si hay ventanas abiertas cuando está activada la climatización.

- Control de la puesta en marcha de electrodomésticos: programando su funcionamiento en horarios en los que el precio de la energía es menor.

- Detección y gestión del consumo "stand by" de los electrodomésticos.

- Monitorización del consumo energético. Esto permite hacer una gestión personalizada del consumo (consumo por franjas horarias, diario, mensual, etc.), así como detectar malos funcionamientos de los equipos del hogar.

\section{Energías renovables}

Si bien todas las seis viviendas de estudio utilizan gas para calentar el agua, el 34\% de encuestados a nivel general de la ciudad utilizan duchas eléctricas, además existe la posibilidad de que se reduzcan o desaparezcan los subsidios al GLP en el Ecuador. Teniendo en cuenta que la radiación solar en Cuenca alcanza valores cerca de 4,350 $\mathrm{Whm}^{2} /$ día (CONELEC, 2008), la cual se considera como intermedia alta, en relación con otros lugares en la región de Sierra, y además se mantiene constante durante todo el año, se recomienda la implementación de sistemas de calentamiento de agua potablea través de 
paneles solares, de manera que se aproveche este recurso. De igual manera se podría aprovechar la radiación solar para generar energía eléctrica a partir de paneles solares fotovoltaicos. Actualmente existen algunos obstáculos en la implementación de esta tecnología en el sector residencial del país, pues, según Sarmiento (2011), si el sistema es aislado de la red tendría un muy alto tiempo de amortización de la inversión. Además, actualmente no existe ningún tipo de incentivo para los costos iniciales de los paneles, ni en caso de venta al estado los $\mathrm{kWh}$ producidos de manera privada. Es decir, en sistema de conexión a red, pues en la Regulación No. CONELEC 001/13 se asignan precios preferentes únicamente a las energías renovables tales como biomasa, biogás e hidroeléctrica, dejando fuera a las eólicas, fotovoltaicas y geotérmicas (CONELEC, 2015b). Por lo tanto, se espera que su utilización en vivienda crezca a medida que bajen los precios de la tecnología fotovoltaica.

\section{Diseño bioclimático}

Según algunos estudios, un buen diseño bioclimático puede conseguir ahorros entre 50 y $70 \%$ para la climatización e iluminación de una vivienda (Ministerio del Ambiente del Ecuador, 2013 \& 2014; Rey $\&$ Velasco, 2006). En una vivienda orientada correctamente se reduciría mucho el consumo de energía eléctrica pues se aprovecharía de manera eficiente la iluminación natural sin necesidad de encender las luces durante el día, como es el caso de las viviendas 2 y 4 (Fig. 8). Según el clima y ubicación de la ciudad de Cuenca las viviendas deberían orientarse en sentido este-oeste tanto para iluminar naturalmente sus espacios como para aprovechar el calor, de preferencia las zonas de descanso hacia el oeste de manera que reciban la radicación solar en horas de la tarde. Así como elegir colores claros en las paredes interiores que reflejen la luz.

Si bien en la ciudad de Cuenca no es común implementar sistemas de climatización, la manera más adecuada de reducir consumo de energía por este servicio es una correcta aislación térmica de la envolvente, en especial la mayor pérdida de calor y filtraciones se produce en los vanos. En relación con los mismos, se aconseja ventanas constituidas por dos hojas de vidrio, separadas entre sí, por una cámara de aire deshidratado que sirve como aislante térmico y acústico, ya que reducen hasta en un $50 \%$ la entrada de frío o calor. En la ciudad de Cuenca, por sus condiciones climáticas se aconseja aprovechar las altas temperaturas y la radiación solar del medio día. Esto permitirá que, a través de una ubicación correcta de los vanos, utilizando materiales de alta inercia térmica como envolvente, exista una rápida captación de calor, la acumulen por unas horas y la transmitan en la noche al interior de la vivienda, que es cuando menores temperaturas se presentan.

\subsection{Definición de estándares}

Como resultado de esta investigación, siguiendo el ejemplo del modelo de clasificación energética de Chile (MINVU, 2013) y el de España (Ruá \& López-Mesa, 2012), se asigna una clasificación del consumo eficiente de energía eléctrica en las viviendas de Cuenca (sin climatización mecánica) la cual se presenta en la Tabla 3, teniendo como media los ahorros alcanzados con las recomendaciones básicas aplicadas en las 6 viviendas de estudio (Fig. 11) lo que representa la calificación "C". Además, se ha comparado el consumo actual de las viviendas con el promedio de la región (Fig. 2), así como con las políticas de subsidios (Fig. 3) para determinar la calificación "D". A continuación, se ha estimado el máximo ahorro posible si se aplicaran otras medidas tecnológicas y de diseño bioclimático, lo que significa la calificación "A", dentro de los estándares propuestos por este estudio. De igual manera se analiza el peor escenario posible, con el fin de establecer el indicador de consumo máximo que representa la calificación " $G$ ", sustituyendo todos los electrodomésticos y luminarias de las 6 viviendas de estudio por equipos de alto consumo. En la Tabla 4 se compara con los sistemas de calificación de Chile y España. 
Tabla 3. Estándares de consumo eficiente de energía eléctrica en las viviendas de Cuenca.

\begin{tabular}{|c|c|c|c|c|c|}
\hline \multicolumn{6}{|c|}{ Clasificación de consumo energético de viviendas sin climatización mecánica en Cuenca, Ecuador } \\
\hline & $\mathrm{kWh} \mathrm{mes}^{-1}$ & $\mathrm{kWh}$ año-1 & $\mathrm{kWh} \mathrm{m}^{-2} \mathrm{año}^{-1}$ & Reducción & En base a \\
\hline A & 60,42 & 725,04 & 5,54 & $70 \%$ & $\begin{array}{l}\text { Aplicación de tecnología, energía renovable } \\
\text { y diseño bioclimático }\end{array}$ \\
\hline B & 90,63 & $1.087,56$ & 8,31 & $55 \%$ & Aplicación de diseño bioclimático \\
\hline $\mathrm{C}$ & 104,99 & $1.259,88$ & 9,78 & $46 \%$ & $\begin{array}{l}\text { Aplicación estrategias básicas (sustitución de } \\
\text { luminarias y electrodomésticos, } \\
\text { aprovechamiento luz natural) }\end{array}$ \\
\hline $\mathrm{D}$ & 181,26 & $2.175,12$ & 16,61 & $10 \%$ & Promedio región \\
\hline $\mathrm{E}$ & 201,40 & $2.416,82$ & 18,46 & $0 \%$ & Consumo base actual \\
\hline $\mathrm{F}$ & 342,38 & $4.108,6$ & 31,38 & $+70 \%$ & Consumo superior intermedio \\
\hline G & 498,17 & $5.978,03$ & 81,95 & $+147.35 \%$ & $\begin{array}{l}\text { Consumo de viviendas sin ningún criterio de } \\
\text { eficiencia (electrodomésticos y luminarias de } \\
\text { alto consumo) }\end{array}$ \\
\hline
\end{tabular}

Tabla 4. Comparación calificación energética de Chile y España.

\begin{tabular}{|c|c|c|c|c|c|c|}
\hline \multirow{2}{*}{$\begin{array}{l}\text { CALIFICACI } \\
\text { ÓN }\end{array}$} & \multicolumn{2}{|c|}{ PROPUESTA CUENCA } & \multicolumn{2}{|r|}{ CEV CHILE } & \multicolumn{2}{|c|}{ CEV ESPAÑA } \\
\hline & & Reducción & & Reducción & & educción \\
\hline A & $70 \%$ & $\begin{array}{l}\text { Aplicación de } \\
\text { tecnología, energía } \\
\text { renovable y diseño } \\
\text { bioclimático }\end{array}$ & $70 \%$ & $\begin{array}{l}\text { Mayor eficiencia } \\
\text { en vivienda, sin } \\
\text { considerar los } \\
\text { costos de inversión }\end{array}$ & $45-58 \%$ & $\begin{array}{l}\text { Más eficientes, } \\
\text { nueva }\end{array}$ \\
\hline B & $55 \%$ & $\begin{array}{l}\text { Aplicación de } \\
\text { diseño bioclimático }\end{array}$ & $56-70 \%$ & Vivienda eficiente & $25-45 \%$ & $\begin{array}{l}\text { construccion o } \\
\text { energías }\end{array}$ \\
\hline $\mathrm{C}$ & $46 \%$ & $\begin{array}{l}\text { Aplicación } \\
\text { estrategias bases }\end{array}$ & $41-51 \%$ & $\begin{array}{l}\text { sin un excesivo } \\
\text { costo de inversión }\end{array}$ & $10-25 \%$ & \\
\hline $\mathrm{D}$ & $10 \%$ & Promedio región & $21-40 \%$ & & $0-10 \%$ & Consumo base \\
\hline $\mathrm{E}$ & $0 \%$ & $\begin{array}{l}\text { Consumo base } \\
\text { actual }\end{array}$ & $0-20 \%$ & $\begin{array}{l}\text { Estándar actual de } \\
\text { construcción (art } \\
\text { 4.1.10 OGUC } \\
2007)\end{array}$ & $\begin{array}{l}0 \text { al } \\
10 \% \\
\text { más }\end{array}$ & $\begin{array}{l}\text { cumplen } \\
\text { requisitos del } \\
\text { Código } \\
\text { Técnico }\end{array}$ \\
\hline $\mathrm{F}$ & $\begin{array}{l}70 \% \\
\text { más }\end{array}$ & $\begin{array}{l}\text { Consumo superior } \\
\text { intermedio }\end{array}$ & $\begin{array}{l}10-34 \% \\
\text { más }\end{array}$ & $\begin{array}{l}\text { Viviendas } \\
\text { construidas con las } \\
\text { exigencias } \\
\text { térmicas OGUC } \\
2001\end{array}$ & $\begin{array}{l}10 \text { a } \\
25 \% \\
\text { más }\end{array}$ & Consumo alto \\
\hline G & $\begin{array}{l}147 \% \\
\text { o más }\end{array}$ & $\begin{array}{l}\text { Consumo de } \\
\text { viviendas sin } \\
\text { ningún criterio de } \\
\text { eficiencia } \\
\text { (electrodomésticos } \\
\text { y luminarias de alto } \\
\text { consumo) }\end{array}$ & $\begin{array}{l}35 \% \text { o } \\
\text { más }\end{array}$ & $\begin{array}{l}\text { Viviendas } \\
\text { construidas sin } \\
\text { exigencias } \\
\text { térmicas }\end{array}$ & $\begin{array}{l}25 \% \text { o } \\
\text { más }\end{array}$ & $\begin{array}{l}\text { de energía, no } \\
\text { cumplen } \\
\text { normativas }\end{array}$ \\
\hline
\end{tabular}

\section{CONCLUSIONES}

- Gracias a las condiciones climáticas y geográficas de la ciudad de Cuenca, el 65\% de los usuarios de las viviendas del sector residencial de la ciudad de Cuenca sienten que su hogar es confortable y solamente el $2 \%$ utiliza algún tipo de calefacción.

- El mayor consumo de electricidad en las viviendas de Cuenca viene dado por los electrodomésticos en un $72 \%$, siendo el refrigerador el que más aporta. 
- El promedio de consumo actual del análisis de las 6 viviendas resulta de $18.46 \mathrm{kWh} \mathrm{m}^{-2}$ año ${ }^{-1}$.

- Si se aplican estrategias básicas como es la sustitución de electrodomésticos y luminarias por equipos eficientes, y si se aprovecha la iluminación natural de manera que no se enciendan las luces en el día, se puede lograr un ahorro promedio de $46 \%$ en el consumo eléctrico total, lo que correspondería a un indicador de $9.78 \mathrm{kWh} \mathrm{m}^{-2}$ año ${ }^{-1}$.

- Quedan pendientes estudios de aplicación real de las estrategias tecnológicas, diseño y energía renovable, a las viviendas en la ciudad de Cuenca con el fin de determinar la reducción real del consumo de energía eléctrica con la aplicación de estas. Al momento se estima que se podría llegar a un $70 \%$ de ahorro si se aplica la tecnología existente y un correcto diseño; si se aplican significaría un indicador de $5.54 \mathrm{kWh} \mathrm{m}^{-2}$ año ${ }^{-1}$.

- El factor económico puede resultar muy influyente al momento de aplicar estrategias de mejora de eficiencia energética en las viviendas de la ciudad de Cuenca, pues, aunque el $32 \%$ lo considera importante, el 66\% no estaría dispuesto a invertir en mejoras para su vivienda.

- Es de suma importancia que el Ecuador implemente un sistema de calificación energética de viviendas además de continuar con la concientización e información sobre buenos hábitos de consumo energético, con el fin de reducir el consumo del sector residencial.

- En otros países se tienen tarifas diferenciadas por horarios, para lo que se aplica la instalación de medidores inteligentes, esta es una medida importante que se recomienda aplicar en nuestro país.

\section{AGRADECIMIENTOS}

Se agradece a la Dirección de Investigación de la Universidad de Cuenca DIUC, por el financiamiento al proyecto "Método de Certificación de la Construcción Sustentable de Viviendas" al cual pertenece este estudio, así como al Centro de Investigación, el Centro de Postgrado y la Maestría en Construcciones de la Facultad de Arquitectura y Urbanismo, Universidad de Cuenca.

\section{REFERENCIAS}

Agencia de Regulación y Control de Electricidad del Ecuador, 2016. Regulación eléctrica. Gobierno del Ecuador. Disponible en de http://www.regulacionelectrica.gob.ec/tarifa-dignidad.

AIHE, 2015. Associacion de la Industria Hidrocarburifera Ecuatoriana. Disponible en http://www.aihe.org.ec.

Aldossary, N.A., Y. Rezgui, A. Kwan, 2015. An investigation into factors influencing domestic energy consumption in an energy subsidized developing economy. Habitat International: A Journal for the Study of Human Settlements, pp. 41-51.

Asamblea Nacional del Ecuador, 2008. Constitución del Ecuador. Montecristi, Ecuador. Disponible en http://www.oas.org/juridico/pdfs/mesicic4_ecu_const.pdf, 136 pp.

Autodesk, 2011. Autodesk® 2011 products. Disponible en http://usa.autodesk.com/adsk/servlet/pc/item?siteID=123112\&id=14991304.

Banco Mundial, 2015. Consumo de energía eléctrica ( $k$ Wh per cápita). Disponible en http://datos.bancomundial.org/indicador/EG.USE.ELEC.KH.PC.

Baquero, M, 2013. Diseño bioclimático de viviendas multifamiliares en la Ciudad de Cuenca. Cuenca, Ecuador: Tesis de Grado, Facultad de Arquitectura y Urbanismo, Universidad de Cuenca.

Barr, S., A. Gilg, N. Ford, 2005. Defining the multi-dimensional aspects of household waste management: A study of reported behavior in Devon. Resources, Conservation and Recycling, 45(2), 172-192. 
Barreto, C., J. Campo, 2012. Relación a largo plazo entre consumo de energía y PIB en América Latina: Una evaluación empírica con datos panel using panel data. Ecos de Economia, 35, 73-89.

BID, 2014. Cuenca ciudad sustentable: Plan de acción. Banco Interamericano de Desarrollo \& Municipalidad de Cuenca. Disponible en http://www.iadb.org/es/temas/ciudades-emergentes-ysostenibles/alcalde-marcelo-cabrera-presenta-plan-de-accion-de-cuenca, 18592.html.

Brunsgaard, C., P. Heiselberg, M-A. Knudstrup, T.S. Larsen, 2011. Evaluation of the indoor environment of comfort houses: Qualitative and quantitative approaches. Indoor and Built Environment, 21(3), 432-451.

Bryman, A, 2008. Secondary analysis and official statistics. In: Bryman, A. (Ed.). Social Research Methods ( $3^{\text {rd }}$ ed.). Oxford, UK: University Press, 312 pp.

CEDOM, 2008. Cómo ahorrar energía instalando domótica en su vivienda. Gane en confort y seguridad. Asociación Española de Domótica \& Instituto para la Diversificación y Ahorra de la Energía. España: AENORediciones. Disponible en http://www.idae.es/uploads/documentos/ documentos_11187_domotica_en_su_vivienda_08_3d3614fe.pdf, 28 pp.

Centrosur, 2015. Energía consumida. Ministerio de Electricidad y Energía Renovable. Disponible en $\mathrm{http} / / / \mathrm{www}$. centrosur.com.ec/?q=energia-consumida.

CONELEC, 2008. Atlas solar del Ecuador. CONELEC. Disponible en http://biblioteca.olade.org/ opac-tmp1/Documentos/cg00041.pdf, 51 pp.

CONELEC, 2015a. Directorio del consejo nacional de electricidad. Consejo Nacional de Electricidad del Ecuador. http://www.conelec.gob.ec.

CONELEC, 2015b. Codificación regulación No. CONELEC - 001/13. Consejo Nacional de Electricidad del Ecuador. Disponible en http://www.regulacionelectrica.gob.ec/wpcontent/uploads/downloads/2015/10/Codificaci\%C3\%B3n-Regulacion-001_13-EnergiasRenovables_.pdf, $23 \mathrm{pp}$.

Cuchí, A, 2003. Los flujos de energía en la edificación. Diplomado internacional. Acercamiento a criterios arquitectónicos ambientales para comunidades aisladas en áreas naturales protegidas de Chiapas Universidad Politécnica de Cataluña.

Dili, A.S., M.A. Naseer, T. Zacharia Varghese, 2010. Passive environment control system of Kerala vernacular residential architecture for a comfortable indoor environment: A qualitative and quantitative analyses. Energy and Buildings, 42(6), 917-927.

De Boeck, L., S. Verbeke, A. Audenaert, L. De Mesmaeker, 2015. Improving the energy performance of residential buildings: A literature review. Renewable and Sustainable Energy Reviews, 52, 960-975.

Forsberg, A., F. von Malmborg, 2004. Tools for environmental assessment of the built environment. Building and Environment, 39(2), 223-228.

Gobierno Nacional del Ecuador, 2011. Norma Ecuatoriana de la Construcción. Capítulo 13:

Eficiencia Energética en la Construcción en Ecuador. Disponible en file:///C:/Users/Jan\%20Feyen/AppData/Local/Microsoft/Windows/INetCache/IE/DN9YSYCV/N EC2011-CAP.13-EFICIENCIA\%20ENERGETICA\%20EN\%20LA\% 20CONSTRUCCION\% 20EN\%20ECUADOR-021412.pdf, 51 pp.

Green Energy Consultants \& Services, 2010. Household energy consumption and use in Peru. Fredericton, New Brunswick, Canada: Environment Canada.

Hernandez, H., L, Meza, 2011. Propuesta de una metodología de certificación de eficiencia energética para viviendas en Chile. Revista de la Construcción, 10(1), 53-63.

IDAE, 2011. Proyecto SECH-SPAHOUSEC: Análisis del consumo energético. Gobierno de España, Ministerio de Industria, Energía y Turismo, Informe final. Disponible en http://www.idae.es/index.php/mod.documentos/mem.descarga?file=/documentos_Informe_SPA HOUSEC_ACC_f68291a3.pdf, 76 pp.

INEC, 2014. Información ambiental en hogares. Instituto Nacional de Estadísticas y Censos del Ecuador. Disponible en http://www.ecuadorencifras.gob.ec/documentos/web- 
inec/Encuestas_Ambientales/Hogares_2014/Documento_tecnico_Modulo_Ambiental_Hogares_ 2014.pdf, 51 pp.

INEC, 2016. Base de datos censo 2016. Instituto Nacional de Estadísticas y Censos del Ecuador. Disponible en http://www.ecuadorencifras.gob.ec/.

INEN, 2009. NTE INEN 2 506:2009: Eficiencia energética en edificaciones. Requisitos ( $1^{\mathrm{a}}$ ed.). Instituto Ecuatoriano de Normalización, Quito, Ecuador. Disponible en https://law.resource.org/ pub/ec/ibr/ec.nte.2506.2009.pdf, 16 pp.

INEN, 2015. Servicios Ecuatoriano de Normalización. Disponible en http://www.normalizacion.gob.ec/.

ISO 15392, 2008. Sustainability in building construction - General principles. Londen, UK. Disponible en http://www.iso.org/iso/catalogue_detail?csnumber=40432, 20 pp.

ISO 21931-1, 2010. Sustainability in building construction - Framework for methods of assessment of the environmental performance of construction works - Part 1: Buildings. Londen, UK. Disponible en http://www.iso.org/iso/catalogue_detail?csnumber=45559, $26 \mathrm{pp}$.

ISO 21929-1, 2011. Sustainability in building construction - Sustainability indicators - Part 1: Framework for the development of indicators and a core set of indicators for buildings. Londen, UK. Disponible en http://www.iso.org/iso/catalogue_detail.htm?csnumber=46599, 39 pp.

Laverge, J., N. Van Den Bossche, N. Heijmans, A. Janssens, 2011. Energy saving potential and repercussions on indoor air quality of demand controlled residential ventilation strategies. Building and Environment, 46(7), 1497-1503.

Lutzenhiser, L, 1992. A cultural model of household energy consumption. Energy, 17(1), 47-60.

Martínez, P.E., 2010. Usos finales de energía eléctrica y GLP en el cantón Cuenca. Escenarios al año 2015. Cuenca, Ecuador: Tesis de maestria, Facultad de Ciencias Químicas, Universidad de Cuenca, 139 pp.

Ministerio de Minas y Energía de Colombia, 2004. Resolución 355 de 2004. Bogotá, Colombia: Ministerio de Minas y Energía, Diario Oficial 45611. Disponible en http://www.alcaldiabogota.gov.co/sisjur/normas/Norma1.jsp?i=14315.

Ministerio del Ambiente del Ecuador, 2013. Implementamos estrategias y medidas que faciliten la adaptación al cambio climático en el manejo del agua. Disponible en http://www.paccecuador.org/.

Ministerio del Ambiente del Ecuador, 2014. Guía practica para el ahorro y uso eficiente de la energía. Consumo eficiente y responsabilidad ambiental. Quito, Ecuador. Disponible en http://www.ambiente.gob.ec/wp-content/uploads/downloads/2014/03/GUIA-PRACTICA-PARAEL-AHORRO-Y-USO-EFICIENTE-DE-ENERGIA-22NovBAJAa.pdf, 48 pp.

Ministerio Coordinador de Sectores Estratégicos, 2015. Catálogo de inversiones de los sectores estratégicos 2015-2017. Disponible en http://www.sectoresestrategicos.gob.ec/wpcontent/uploads/downloads/2015/04/Primera-parte-Cata\%CC\%81logo-de-Inversiones-de-losSectores-Estrate\%CC\%81gicos-2015-2017.pdf, 64 pp.

Ministerio de Energía de Chile, 2015. Chile renueva sus energías. Disponible en http://www.chilerenovables.cl/chile-renueva-sus-energias/.

Ministerio de Fomento de España, 2013. Documento Básico DB-HE "Ahorro de Energía", del Código Técnico de la Edificación. Boletin Oficial del Estado, No. 219.

Ministerio de Fomento de España, 2015. CTE Código Técnico de la Edificación. Disponible en http://www.codigotecnico.org/index.php/.

MINVU, 2013. Manual de procedimiento para la calificacion energetica de viviendas en Chile. Ministerio de Vivienda y Urbanismo Chile, Santiago, Chile. Disponible en $\mathrm{http} / / / \mathrm{www}$.acee.cl/tag/manual-de-procedimientos-para-la-calificacion-energetica-de-viviendasen-chile/.

MINVU, 2014. Calificación energética de viviendas. Ministerio de Vivienda y Urbanismo Chile, Santiago, Chile. Disponible en http://calificacionenergetica.minvu.cl/. 
MINETUR, 2015. Certificación de eficiencia energética de los edificios. Ministerio de Industria Energía y Turismo de España. Disponible en http://www.minetur.gob.es/.

ONU, 2016. Departamento de Asuntos Económicos y Sociales. División de Desarrollo sostenible. Disponible en http://www.un.org/spanish/esa/sustdev/agenda21/.

OSINERGMIN, 2013. Acceso a la energía en el Perú: Balance y opciones. Congreso Internacional sobre Acceso Universal a los Servicios Públicos de Energía. Lima, Perú: Organismo Supervisor de la Inversión en Energía y Minería del Perú.

Pérez-Lombard, L., J. Ortiz, C. Pout, 2008. A review on buildings energy consumption information. Energy and Buildings, 40(3), 394-398.

Pinilla, A.M., C.C. Orosa, 2011. Manual Técnico BREEAM® ES Vivienda, 314 pp. Disponible en http://www.breeam.es/index.php/extranet-breeam/extranet/manuales-tecnicosbreeam/vivienda/manual-tecnico-breeam-es-vivienda/download.

QUALITEL Association, 2012. Qualitel: Habitat \& Environment. Disponible en http://www.qualitelogement.org/certification-et-labels/connaitre-les-certifications-de-qualite-neuf/autrescertifications/qualitel-habitat-environnement.html.

Quesada, F., 2014. Métodos de evaluación sostenible de la vivienda: Análisis comparativo de cinco métodos internacionales. Hábitat Sustentable, 4(1), 56-67.

Rey, F.J., E. Velasco, 2006. Eficiencia energética en edificios. Certificación y auditorías energéticas. Madrid, España: Thomson Editores, 330 pp..

Robledo, J.C., W. Olivares, 2013. Relación entre las emisiones de $\mathrm{CO}_{2}$. El consumo de energía y el PIB: El Caso. Semestre Económico, 16(33), 45-65.

Ruá, M.J., B. López-Mesa, 2012. Certificación energética de edificios en España y sus implicaciones económicas. Informes de La Construcción, 64(527), 307-318.

Sarmiento J,M.F., 2011. Análisis de factibilidad tecnica y económica de la implementación de energía fotovoltacia y termosolar para generación de electricidad y calentamiento de agua mediante paneles fijos y un seguidor de sol de cosntrucción casera, para vivienda unifamiliar. Tesis previa a la obtención de grado de Ingeniero Civil, Facultad de Ingenieria Civil, Universidad de Cuenca.

SENER, 2011. Indicadores de eficiencia energética para el sector residencial. Taller de Indicadores de Eficiencia Energética. México D.F., México. Disponible en https://www.gob.mx/cms/uploads/attachment/file/85305/Bibliograf_a_6.pdf, 168 pp.

SUI, 2015. Reporte general del promedio de consumo residencial urbano. Bogotá, Colombia: Sistema Unico de Información de Servicios Públicos de Colombia, Gobierno de Colombia.

Taleb, H.M., S. Sharples, 2011. Developing sustainable residential buildings in Saudi Arabia: A case study. Applied Energy, 88(1), 383-391.

Thiers, S., B. Peuportier, 2012. Energy and environmental assessment of two high energy performance residential buildings. Building and Environment, 51, 276-284.

Unidad de Planeación Minero Energética, 2014. Guía para el consumo consciente, racional y eficiente de la energía. Disponible en http://www.rmi.org/Content/Files/SECTOR\%20RESIDENCIAL.pdf, 68 pp.

United Nations, 2015. World population prospects: The 2015 revision. UN: Department of Economic and Social Affairs. Disponible en https://esa.un.org/unpd/wpp/.

United States Census Bureau, 2015. U.S. and world population clock. Disponible en http://www.census.gov/popclock/. 